\section{Seed Germination of Huagaimu, a Critically Endangered Plant Endemic to Southeastern Yunnan, China}

\author{
Yan-Ling Zheng ${ }^{1,2}$ and Wei-Bang Sun ${ }^{1,3}$
}

AdDITIONAL InDEx wORDs. GA, Magnoliaceae, Manglietiastrum sinicum, moist chilling, propagation, seed dormancy

SuMMARY. As a critically endangered tree in the Magnoliaceae family, huagaimu (Manglietiastrum sinicum) is represented by only 10 mature individuals in evergreen broadleaved montane forests of southeastern Yunnan Province, China. Our previous work revealed the existence of a seed dormancy period for this species. The current study was performed to evaluate the effects of plant growth regulators (PGRs) and moist chilling on breaking seed dormancy in this species. Germination of seeds pretreated for $24 \mathrm{~h}$ with gibberellic acid $\left(\mathrm{GA}_{3}\right), \alpha$-naphthaleneacetic acid, 6-benzyladenine, and 2,4-dichlorophenoxyacetic acid indicated that only $\mathrm{GA}_{3}$, at concentrations of 300 and $500 \mathrm{mg} \cdot \mathrm{L}^{-1}$, can significantly break the seed dormancy of huagaimu after 50 days of incubation, with about $66 \%$ germination under 500 $\mathrm{mg} \cdot \mathrm{L}^{-1} \mathrm{GA}_{3}$. Moist chilling at $4{ }^{\circ} \mathrm{C}$ for 3 weeks can also effectively break the seed dormancy of the species, with $56 \%$ of seeds treated in this way germinating after 30 days of incubation. The combined treatments of PGRs followed by moist chilling were also conducted. Based on germination results after $\mathbf{3 0}$ days of incubation, the seed germination of combined treatments was significantly higher than that of PGR treatments. However, the seeds treated only with moist chilling presented the highest germination percentage among all the treatments.

$\mathrm{T}$ The generic delimitation of Magnoliaceae has long been debated. Figlar and Nooteboom (2004) classified only two genera in the family, Magnolia and Liriodendron. However, Xia (2007) has comprehensively revised the family (particularly for the Chinese taxa), and 17 genera have been recognized. Manglietiastrum sinicum was proposed as a species of a monotypic genus in the Magnoliaceae family (Law, 1979). It also was treated taxonomically as Manglietia sinica (Chen and Nooteboom, 1993), Magnolia sinica (Cicuzza et al., 2007; Figlar and Nooteboom, 2004), and Pachylarnax sinica (Xia, 2007). The genus Manglietiastrum has been widely accepted in China (Kunming Institute of Botany, 2006), and morphologically it is highly distinguishable; therefore, $M$. sinicum is used in this article. In the past two decades, field surveys have been continuously

\footnotetext{
We thank Heather Barrett-Mold for her assistance in improving our writing.

${ }^{1}$ Kunming Institute of Botany, Chinese Academy of Sciences, Kunming, 650204, People's Republic of China

${ }^{2}$ Graduate School of Chinese Academy of Sciences, Beijing, 100039, People's Republic of China

${ }^{3}$ Corresponding author. E-mail: wbsun@mail.kib.ac.cn.
}

conducted and only approximately 10 large mature trees have been found in the broadleaved evergreen montane forests in southeastern Yunnan Province of China (Cicuzza et al., 2007). Huagaimu has attractive fragrant flowers, a beautiful crown, and shiny leaves, and as such, it is an ideal landscaping tree. Also, the species has a straight trunk and silky textured wood, and in the past has been used as a timber tree. Because of its rarity, habitat destruction, and botanical importance, huagaimu has been proposed as the first-ranked priority for China's National Protection (National Forestry Bureau and Agriculture Ministry of China, 1999), and it is also currently being evaluated as a critically endangered species globally (Cicuzza et al., 2007).

Propagation from seeds is important for huagaimu. During the investigations for carrying out the Fauna and Flora International (FFI)China Magnolia Program, we found about 5000 saplings of huagaimu in several local nurseries. The saplings were from seeds commonly sown in native loess, and the seeds normally took almost half a year to germinate. However, the relevant information of seed biology and germination physiology have not yet been recorded.

Seed germination is an intricate biochemical process involving a complex of morphological, physiological, and biochemical changes in the embryo. Failure to germinate when environmental conditions are adequate is called dormancy (Bewley, 1997). Seed dormancy is an adaptive trait common to many plant species. The extent and persistence of dormancy is genetically controlled and highly dependent on environmental conditions before and after seed maturation (Bethke et al., 2004). Various dormancy breaking and germination stimulating treatments have been tried with seeds of a wide range of species. In this respect, plant growth regulators (PGRs) and low temperatures have been studied intensively. PGRs are essential in all physiological and developmental processes occurring during plant growth. Levels of endogenous PGRs such as gibberellic acids (GAs), cytokinins (CTKs), and ethylene are believed to play a major role in breaking seed dormancy. Numerous researchers have found that exogenously applied GAs can overcome dormancy in many plant species (Arnold et al., 1996; Delanoy et al., 2006; Gupta, 2003; Nadjafi et al., 2006; van Staden, 1973). In addition, GAs are thought to stimulate germination by promoting the mobilization of stored food reserves (Adkins et al., 2002). Although more than 100 members of GAs are now known, $\mathrm{GA}_{3}, \mathrm{GA}_{4}$, and $\mathrm{GA}_{7}$ are most frequently used exogenously to break seed dormancy. CTKs usually display low activity in dormancy and germination control compared with GAs; however, they are more effective than GAs in counteracting inhibitors of various GA-sensitive processes (Leadem,

\begin{tabular}{llll}
\hline $\begin{array}{l}\text { Units } \\
\text { To convert U.S. to SI, } \\
\text { multiply by }\end{array}$ & U.S. unit & SI unit & $\begin{array}{l}\text { To convert SI to U.S., } \\
\text { multiply by }\end{array}$ \\
\hline 2.54 & inch $(\mathrm{es})$ & $\mathrm{cm}$ & 0.3937 \\
25.4 & inch $(\mathrm{es})$ & $\mathrm{mm}$ & 10.0394 \\
1 & $\mathrm{ppm}$ & $\mathrm{mg} \cdot \mathrm{L}^{-1}$ & 1 \\
$\left({ }^{\circ} \mathrm{F}-32\right) \div 1.8$ & ${ }^{\circ} \mathrm{F}$ & ${ }^{\circ} \mathrm{C}$ & $\left(1.8 \times{ }^{\circ} \mathrm{C}\right)+32$
\end{tabular}


1987). Webb and Wareing (1972) also found that exogenous application of kinetin to dormant sycamore seeds increased germination whereas $\mathrm{GA}_{3}$ had no effect. On the other hand, in light-requiring seeds, GAs often induce high germination in darkness, whereas CKs generally require some irradiation or the presence of GAs (Thomas, 1992). Therefore, different mechanisms of breaking seed dormancy might exist between GAs and CTKs. Khan (1975) reported that GAs and CTKs take on primary and permissive roles, respectively, in regulating seed germination. Auxins play a major role in a variety of growth and developmental processes in plants by regulating cell division, elongation, and differentiation (Becker and Hedrich, 2002). Nevertheless, there are very few reports on the role of synthetic auxins in controlling seed dormancy. It has been pointed out that auxins such as 2,4-dichlorophenoxyacetic acid $(2,4-\mathrm{D})$ and $\alpha$-naphthaleneacetic acid (NAA) can promote biosynthesis of ethylene (Arteca, 1982; Balagué and Pech, 1985), and ethylene is involved in the promotion of seed germination (Gniazdowska et al., 2007; Kępczyński et al., 2003, 2006a, 2006b). Therefore, in the present study, NAA and 2,4-D were employed to test their effects on release of seed dormancy of huagaimu. Moist chilling, as an external stimulus, is often effective on breaking seed dormancy and results in enhanced seed germination, seedling emergence, or both. Bradbeer (1968) reported that the essential effect of chilling on intact hazel seeds may be to activate the mechanism for gibberellin synthesis, and Villiers and Wareing (1960) observed that the embryo of ash (Fraxinus excelsior) produced stimulating substances counteracting the inhibitors present in the embryo and endosperm during the chilling treatment.

Seed dormancy is a common phenomenon in the Magnoliaceae family, and our previous observations indicated that seeds of huagaimu also exhibit dormancy (Zheng et al., 2008). The reports indicated that dormancy of some species from Magnoliaceae can be effectively broken by GAs and low-temperature treatments (Guo et al., 2006; Han, 2008; Zhou, 1991). The objective of this study was to test whether exogenous PGRs and moist chilling could break the seed dormancy of huagaimu and to find a practical protocol of speeding the seed germination of the species.

\section{Materials and methods}

SEED SOURCE AND SEED STERILIZATION. Seeds were collected from the nature reserve in southeastern Yunnan China (lat. $22^{\circ} 51^{\prime} \mathrm{N}$, long. $104^{\circ} 01^{\prime} \mathrm{E}$ ) in 2007 . Seeds without arils were stored at $4{ }^{\circ} \mathrm{C}$ until use (about $\mathrm{l}$ week). These seeds were sterilized by soaking in $1 \%$ potassium permanganate $\left(\mathrm{KMnO}_{4}\right)$ for $10 \mathrm{~min}$, and were then rinsed thoroughly with sterile distilled water before applying any treatment.

Treatment of PGRs. The sterilized seeds were soaked in aqueous solutions of 2,4-D (100 mg. $\left.\mathrm{L}^{-1}\right)$, NAA (100 $\left.\mathrm{mg} \cdot \mathrm{L}^{-1}\right), 6$-benzyladenine [6-BA $\left.\left(100 \mathrm{mg} \cdot \mathrm{L}^{-1}\right)\right], \mathrm{GA}_{3}(100$, 300 , and $500 \mathrm{mg} \cdot \mathrm{L}^{-1}$ ), and distilled water (control) for $24 \mathrm{~h}$ before for germination tests.

Treatment OF MOIST CHILLING. The sterilized seeds were first soaked in distilled water (control) or various aqueous solutions of PGRs (as shown in Table 1) for $24 \mathrm{~h}$. The seeds were then placed on filter papers $(12.5 \mathrm{~cm}$ in diameter) in petri dishes and moistened with distilled water. Petri dishes containing the seeds were kept at $4 \pm$
$1{ }^{\circ} \mathrm{C}$ in darkness in a refrigerator for 3 weeks before germination tests.

Germination tests. Twentyfive seeds from each of the 14 treatments were sampled for germination tests, and four replications of each treatment were conducted. The seeds were placed on the top of two layers of filter papers, previously moistened with distilled water in petri dishes. The petri dishes were placed in a germination chamber at a constant temperature of $25^{\circ} \mathrm{C}$ with a 12 -h photoperiod provided by fluorescent lights $\left(25 \mu \mathrm{mol} \cdot \mathrm{m}^{-2} \cdot \mathrm{s}^{-1}\right)$. Water was added as necessary to maintain moistness. Radicle protrusion of $2 \mathrm{~mm}$ was the criterion of germination and the germinated seeds were counted after 30 or $50 \mathrm{~d}$ of incubation.

EXPERIMENTAL DESIGN AND DATA ANALYSIS. All of the experiments were carried out using a completely random design. Significance of the treatments was determined by analysis of variance (ANOVA) and the differences between the means were compared by Fisher's least significant difference (LSD) test. As some seeds treated with combination of NAA and moist chilling were infected by fungi during germination, the corresponding data were not collected. To compare the effects of PGRs (except NAA) only and combination of PGRs and moist chilling on breaking seed dormancy, germination results after

Table 1. Germination percentage of huagaimu (Manglietiastrum sinicum) seeds treated with plant growth regulators only $(\mathrm{H})$ or plant growth regulators followed by moist chilling $(\mathrm{H}+\mathrm{MC})$. Seeds were soaked for $24 \mathrm{~h}$ in plant growth regulators or distilled water (control) before initiating germination test or moist chilling treatments at $4{ }^{\circ} \mathrm{C}\left(39.2{ }^{\circ} \mathrm{F}\right)$ for $21 \mathrm{~d}$. Germination was assessed at $30 \mathrm{~d}$ after seed soak (DAS) and $30 \mathrm{~d}$ after initiating germination (DAI) for one $\mathrm{H}$ treatment $(\mathrm{H}-30)$, at $50 \mathrm{DAS}$ and $50 \mathrm{DAI}$ for the second $\mathrm{H}$ treatment $(\mathrm{H}-50)$, and at 51 DAS and $30 \mathrm{DAI}$ for the $\mathrm{H}+\mathrm{MC}$ treatment.

\begin{tabular}{lcccc}
\hline Plant growth & & \multicolumn{3}{c}{ Germination (\%) } \\
\cline { 3 - 5 } regulators $^{\mathrm{z}}$ & Concn $\left(\mathbf{m g} \cdot \mathrm{L}^{-1}\right)^{\mathrm{y}}$ & $\mathrm{H}-\mathbf{3 0}$ & $\mathrm{H}-\mathbf{5 0}$ & $\mathrm{H}+\mathbf{M C}$ \\
\hline Water & & $2 \mathrm{~cd}^{\mathrm{x}}$ & $7 \mathrm{c}$ & $56 \mathrm{a}$ \\
$2,4-\mathrm{D}$ & 100 & $0 \mathrm{~d}$ & $2 \mathrm{~d}$ & $10 \mathrm{~d}$ \\
$\mathrm{NAA}$ & 100 & $3 \mathrm{c}$ & $6 \mathrm{c}$ & $-{ }^{\mathrm{w}}$ \\
$6-\mathrm{BA}$ & 100 & $4 \mathrm{c}$ & $9 \mathrm{c}$ & $15 \mathrm{c}$ \\
$\mathrm{GA}_{3}$ & 100 & $7 \mathrm{bc}$ & $37 \mathrm{bc}$ & $17 \mathrm{c}$ \\
$\mathrm{GA}_{3}$ & 300 & $12 \mathrm{~b}$ & $64 \mathrm{a}$ & $41 \mathrm{~b}$ \\
$\mathrm{GA}_{3}$ & 500 & $24 \mathrm{a}$ & $66 \mathrm{a}$ & $53 \mathrm{a}$ \\
$P$ & & 0.00 & 0.00 & 0.00 \\
\hline
\end{tabular}

${ }^{\mathrm{z}} 2,4$-D $=2$,4-dichlorophenoxyacetic acid; NAA $=\alpha$-naphthaleneacetic acid; 6 - $\mathrm{BA}=6$-benzyladenine; $\mathrm{GA}_{3}=$ gibberellic acid.

${ }^{y} \mathrm{mg} \cdot \mathrm{L}^{-1}=1 \mathrm{ppm}$.

${ }^{x}$ Values represent means of four replicates of 25 seeds; means followed by different letters within a column are significantly different according to the Fisher's least significant difference test at $P=0.05$.

"Some seeds subjected to the treatment (combination of NAA and moist chilling) were infected by fungi; therefore, data were not collected. 
$30 \mathrm{~d}$ of incubation were compared by Student's $t$ test. Data given in percentages were subjected to arcsine transformation before statistical analysis.

\section{Results and discussion}

PGRs showed significant difference in breaking seed dormancy of huagaimu. Of all PGRs tested, only $\mathrm{GA}_{3}$ showed a positive response in breaking the seed dormancy compared with the treatment of distilled water (control). In contrast, NAA and 6-BA did not show a significant influence, and 2,4-D significantly suppressed the seed germination with only $2 \%$ germination after $50 \mathrm{~d}$ of incubation (Table 1). Contrary to the present results, seeds soaking with $100 \mathrm{mg} \cdot \mathrm{L}^{-1}$ NAA could increase the germination percentage of queen palm (Syagrus romanzoffiana) and dwarf sugar palm (Arenga engleri) (Liang and Yang, 2005). NAA can also significantly stimulate seed germination of fragrant anneslea (Anneslea fragrans); however, at a lower concentration of $5 \mathrm{mg} \cdot \mathrm{L}^{-1}$ (Shen et al., 2008). Wang et al. (2005) also reported the positive effect of 2,4-D on the seed germination of rhodiola (Rhodiola rosea). It could be induced that auxins play a role in breaking seed dormancy; however, the effective concentration is species-dependent. It was also reported that the action of various PGRs is concentrationdependent (Goeschl and Kays, 1975; Mulkey et al., 1982; Raghavan et al., 2006). Therefore, the failure of tested auxins in promoting the seed germination of huagaimu might be due to the improper concentration. CTKs are frequently employed to break seed dormancy and many reports showed that CTKs can counteract the germination inhibitors (Białecka and Kępczyński, 2003; Thomas et al., 1986; Webb and Wareing, 1972). Our previous study (Zheng et al., 2008) also revealed that inhibitory substances existed in different seed parts of huagaimu. Therefore, 6-BA was tested presently; however, it did not show a positive effect on promotion of seed germination. The possibility of ineffectiveness of 6-BA on seed dormancy-breaking of huagaimu is that the concentrations chosen for this species were not effective. Brady and McCourt (2003) have reported on the interaction of PGRs in seed dormancy. It is possible that the exogenous application of NAA, 6-BA, and 2,4-D within the tested concentrations did not affect the initial balance of PGRs contained in the seeds or strengthened the effect of the germination inhibitors such as $\mathrm{ABA}$ and some other chemical compounds.

Seed germination was significantly affected by treatments of different $\mathrm{GA}_{3}$ concentrations. Germination percentages of $24 \%, 12 \%$, and $7 \%$ were obtained after $30 \mathrm{~d}$ of incubation under $\mathrm{GA}_{3}$ concentrations of 500 , 300 , and $100 \mathrm{mg} \cdot \mathrm{L}^{-1}$, respectively. At day 50, the germination percentages of the seeds treated with 500 and $300 \mathrm{mg} \cdot \mathrm{L}^{-1} \mathrm{GA}_{3}$ were almost same (i.e., $66 \%$ and $64 \%$, respectively); however, only $37 \%$ of seeds germinated under treatment of 100 $\mathrm{mg} \cdot \mathrm{L}^{-1} \mathrm{GA}_{3}$ (Table $\mathrm{l}$ ). Soaking seeds in aqueous solutions of GAs can effectively break the seed dormancy of some Magnoliaceae plant species; however, the effective concentration of GAs is specific to species (Guo et al., 2006; Han, 2008; Zhou, 1991). For example, 100 to 200 $\mathrm{mg} \cdot \mathrm{L}^{-1} \mathrm{GA}_{3}$ can effectively break the seed dormancy of champaca (Michelia champaca) and qiuhua michelia (Michelia sphaerantha), respectively. Germination of both species was suppressed by a higher concentration of $\mathrm{GA}_{3}$ (Han, 2008). For chuandian manglietia (Manglietia duclouxii) and yunnan michelia (Michelia yunnanensis), the optimal concentrations of $\mathrm{GA}_{3}$ are 2500 and $1000 \mathrm{mg} \cdot \mathrm{L}^{-1}$, respectively (Han, 2008). Exogenous GAs, although leading to a fast response in seed germination, can induce different substantial long-lasting effects on the growing plantlet morphogenesis, with possible interference in their survival capacity (Evans et al., 1996; Rascio et al., 1998). Therefore, GA application is valid only if there are no side effects of GA on seedling morphology. When the present germination data were collected, the induced seedlings of huagaimu were planted in laterile and more than $90 \%$ of total seedlings survived after $30 \mathrm{~d}$ of growth. However, the morphological effects of various treatments were not observed in detail. In addition, no relevant information was recorded in other species of Magnoliaceae. As such information is essential to test the applicability of each treatment to induce normal seedlings, it should be considered in a future study. Also, the presently tested concentration of $\mathrm{GA}_{3}$ is only up to $500 \mathrm{mg} \cdot \mathrm{L}^{-1}$; the effect of higher concentration of $\mathrm{GA}_{3}$ on breaking seed dormancy also needs to be determined.

Treatment of moist-chilling alone (control) can also break seed dormancy, with $56 \%$ of the seeds germinating after $30 \mathrm{~d}$ of incubation. When the seeds were soaked in different aqueous solutions of PGRs for $24 \mathrm{~h}$ before moist chilling, seed germination was significantly inhibited by $100 \mathrm{mg} \cdot \mathrm{L}^{-1} 6-\mathrm{BA}, \mathrm{GA}_{3}$, and $2,4-\mathrm{D}$, and $300 \mathrm{mg} \cdot \mathrm{L}^{-1} \mathrm{GA}_{3}$, compared with the control, with the germination percentage ranging from $10 \%$ to $41 \%$. Although pretreatment of $500 \mathrm{mg} \cdot \mathrm{L}^{-1}$ $\mathrm{GA}_{3}$ also inhibited germination compared with moist chilling alone, the inhibitory effect was not significant (Table 1).

Based on germination results after $30 \mathrm{~d}$ of incubation, the seed germination percentage of combined treatments of PGRs followed by moist chilling was significantly higher than that of PGRs only. However, the seeds treated only with moist chilling induced the highest germination among all the treatments (Table 1 ). This suggested that effects of PGRs on stimulating seed germination of huagaimu may interact with the temperature. Hilhorst and Karssen (1992) also reported that both synthesis of and responsiveness to PGRs are controlled by environmental factors including temperature. In the present study, only one moist chilling period was tested. Fang et al. (2006) and Rehman and Park (2000) reported that the combination of $\mathrm{GA}_{3}$ and moist chilling treatments produced differential effects on seed germination percentage depending on the length of the moist chilling period. For huagaimu, differential results might also be obtained if the moist chilling period is changed. In conclusion, exogenous $\mathrm{GA}_{3}$ and moist chilling can effectively break seed dormancy of huagaimu. However, the postgermination traits should be observed to see whether there are phenotypic side effects of each treatment to judge their validity. In addition, the type and mechanism of the seed dormancy of the species need to be deeply studied. 


\section{Literature cited}

Adkins, S.W., S.M. Bellairs, and D.S. Loch. 2002. Seed dormancy mechanisms in warm season grass species. Euphytica 126:13-20.

Arnold, R.M., J.A. Slyker, and T.H. Gupta. 1996. Germination of Chaenorrbinum minus seeds in response to gibberellin treatments. J. Plant Physiol. 148:677-683.

Arteca, R.N. 1982. Influence of IAA, NAA and 2,4-D on ethylene production by potato discs (Solanum tuberosum L. cv. Red Pontiac). Amer. J. Potato Res. 59: 267-274.

Balagué, C. and J.C. Pech. 1985. Relationship between the activity of the ethyleneforming enzyme and the level of intracellular 2,4-dichlorophenoxyacetic acid in pear cell cultures in vitro. J. Plant Growth Regul. 4:81-89.

Becker, D. and R. Hedrich. 2002. Channelling auxin action: Modulation of ion transport by indole-3-acetic acid. Plant Mol. Biol. 49:349-356.

Bethke, P.C., F. Gubler, J.V. Jacobsen, and R.L. Jones. 2004. Dormancy of Arabidopsis seeds and barley grains can be broken by nitric oxide. Planta 219:847-855.

Bewley, J.D. 1997. Seed germination and dormancy. Plant Cell 9:1055-1066.

Białecka, B. and J. Kępczyński. 2003. Endogenous ethylene and reversing methyl jasmonate inhibition of Amaranthus caudatus seed germination by benzyladenine or gibberellin. Plant Growth Regulat. 41:712.

Bradbeer, J.W. 1968. Studies in seed dormancy. IV. The role of endogenous inhibitors and gibberellin in the dormancy and germination of Corylus avellana L. seeds. Planta 78:266-276.

Brady, S.M. and P. McCourt. 2003. Hormone cross-talk in seed dormancy. J. Plant Growth Regul. 22:25-31.

Chen, B.L. and H.P. Nooteboom. 1993. Notes on Magnoliaceae III: The Magnoliaceae of China. Ann. Mo. Bot. Gard. 80: 999-1104.

D. Cicuzza, A. Newton, and S. Oldfield (eds.). 2007. The red list of Magnoliaceae. Lavenham Press, Cambridge, UK.

Delanoy, M., P. van Damme, X. Scheldeman, and J. Beltran. 2006. Germination of Passiflora mollissima (Kunth) L.H. Bailey, Passiflora tricuspis Mast. and Passiflora nov sp. seeds. Scientia Hort. 110:198-203.

Evans, A.S., R.J. Mitchell, and R.J. Cabin. 1996. Morphological side effects of using gibberellic acid to induce germination: Consequences for the study of seed dormancy. Amer. J. Bot. 83:543-549.
Fang, S.Z., J.Y. Wang, Z.Y. Wei, and Z.X. Zhu. 2006. Methods to break seed dormancy in Cyclocarya paliurus (Batal). Iljinskaja. Scientia Hort. 110:305-309.

Figlar, R.B. and H.P. Nooteboom. 2004. Notes on Magnoliaceae IV. Blumea 49:87-100.

Gniazdowska, A., U. Dobrzyńska, T. Babańczyk, and R. Bogatek. 2007. Breaking the apple embryo dormancy by nitric oxide involves the stimulation of ethylene production. Planta 225:1051-1057.

Goeschl, J.D. and S.J. Kays. 1975. Concentration dependencies of some effects of ethylene on etiolated pea, peanut, bean and cotton seedlings. Plant Physiol. 55:670-677.

Guo, Y.Q., Y.B. Shen, F.Y. Yu, and N.J. Lang. 2006. Study on dormant control of Liriodendron tulipifera seed (in Chinese). J. Zhejiang For. Sci. Technol. 26:3840 .

Gupta, V. 2003. Seed germination and dormancy breaking techniques for indigenous medicinal and aromatic plants. J. Medicinal Aromatic Plant Sci. 25:402407.

Han, C.Y. 2008. Seed dormancy and germplasm preservation of Magnoliaceaous plants (in Chinese). Kunming Institute of Botany, Chinese Academy of Sciences, Yunnan, China, Ph.D. Diss.

Hilhorst, H.W.M. and C.M. Karssen. 1992. Seed dormancy and germination: The role of abscisic acid and gibberellins and the importance of hormone mutants. Plant Growth Regulat. 11:225-238.

Kępczyński, J., B. Białecka, M.E. Light, and J. van Staden. 2006a. Regulation of Avena fatua seed germination by smoke solutions, gibberellin $A_{3}$ and ethylene. Plant Growth Regulat. 49:9-16.

Kępczyński, J., E. Kępczyńska, and M. Bihun. 2003. The involvement of ethylene in the release of primary dormancy in Amaranthus retroflexus seeds. Plant Growth Regulat. 39:57-62.

Kępczyński, J., M. Bihun, and E. Kępczyńska. 2006b. Implication of ethylene in the release of secondary dormancy in Amaranthus caudatus L. seeds by gibberellins or cytokinin. Plant Growth Regulat. 48:119-126.

Khan, A.A. 1975. Primary preventive and permissive roles of hormones in plant systems. Bot. Rev. 41:391-420.

Kunming Institute of Botany. 2006. Flora yunnanica. Science Press, Beijing, China.

Law, Y.W. 1979. A new genus of Magnoliaceae from China. Acta Phytotaxonomica Sinica 17:72-74.
Leadem, C.L. 1987. The role of plant growth regulations in the germination of forest tree seeds. Plant Growth Regulat. 6:61-93.

Liang, Y.Q. and S.C. Yang. 2005. Seed dormancy mechanism and ways to accelerate germination of Syagrus romanzoffiana and Arenga engleri (in Chinese). Subtropical Plant Sci. 34:20-24.

Mulkey, T.J., K.M. Kuzmanoff, and M.L. Evans. 1982. Promotion of growth and shift in the auxin dose/response relationship in maize roots treated with the ethylene biosynthesis inhibitors aminoethoxyvinylglycine and cobalt. Plant Sci. Lett. 25: $43-48$.

Nadjafi, F., M. Bannayan, L. Tabrizi, and M. Rastgoo. 2006. Seed germination and dormancy breaking techniques for Ferula gummosa and Teucrium polium. J. Arid Environ. 64:542-547.

National Forestry Bureau and Agriculture Ministry of China. 1999. List of national key protected wild plants (first group). National Forestry Bureau and Agriculture Ministry of China, Beijing, China.

Raghavan, C., E.K. Ong, M.J. Dalling, and T.W. Stevenson. 2006. Regulation of genes associated with auxin, ethylene and ABA pathways by 2,4-dichlorophenoxyacetic acid in Arabidopsis. Funct. Integr. Genomics 6:60-70.

Rascio, N., P. Mariani, F.D. Vecchia, N.L. Rocca, P. Profumo, and P. Gastaldo. 1998. Effect of seed chilling or $\mathrm{GA}_{3}$ supply on dormancy breaking and plantlet growth in Cercis siliquastrum L. Plant Growth Regulat. 25:53-61.

Rehman, S. and I.H. Park. 2000. Effect of scarification, GA and chilling on the germination of goldenrain-tree (Koelveuteria paniculata Laxm.) seeds. Scientia Hort. 85:319-324.

Shen, G.Z., X.Y. Liu, S.K. Shen, Y.R. Wum, and Y.H. Wang. 2008. Effect of 6-BA and NAA on germination characters of Anneslea fragrans Wall seed (in Chinese). Seed 27:73-74.

Thomas, T.H. 1992. Some reflections on the relationship between endogenous hormones and light-mediated seed dormancy. Plant Growth Regulat. 11:239-248.

Thomas, T.H., A.S. Dearman, and N.L. Biddington. 1986. Evidence for the accumulation of a germination inhibitor during progressive thermoinhibition of seeds of celery (Apium graveolens L.). Plant Growth Regulat. 4:177-184.

van Staden, J. 1973. Changes in endogenous cytokinins of lettuce seed during germination. Physiol. Plant. 28: 222-227. 
Villiers, T.A. and P.F. Wareing. 1960. Interaction of growth inhibitor and a natural germination stimulator in the dormancy of Fraxinus excelsior L. Nature 185:112-114.

Wang, Q., X. Ruan, and Q.C. Yan. 2005. Study on the effect of plant hormones and pre-chilled treatment to break dormancy and germination of Rhodiola rosea seeds (in Chinese). J. Zhejiang Univ. 31:423-432.
Webb, D.P. and P.F. Wareing. 1972. Seed dormancy in Acer: Endogenous germination inhibitors and dormancy in Acer pseudoplatanus L. Planta 104: 115-125.

Xia, N.H. 2007. Taxonomic revision on the family Magnoliaceae from China (in Chinese). Ph.D. Diss., Kunming Institute of Botany, Chinese Academy of Sciences, Yunnan, China.
Zheng, Y.L., W.B. Sun, and X.F. Zhao. 2008. Seed dormancy and germination of Manglietastrum sinicum Law, a globally critical endangered plant in China (in Chinese). Plant Physiol. Commun. 44:100102.

Zhou, Y.X. 1991. Preliminary study on the characters of dormancy and germination of Manglietia insignis seed (in Chinese). Seeds 6:10-13. 